\title{
BIBLIOGRAFÍA SOBRE PABLO NERUDA Y SU OBRA $(2005-2009)^{1}$
}

\section{OBRAS}

1. VeINTE POEMAS DE AMOR Y UNA CANCIÓN DESESPERADA

Albala, Eliana. "Veinte poemas de amor: un libro perfecto". Anales de Literatura Chilena 6 (2005): 191-198.

Bohorques Marchori, Lupe. La imagen de la mujer en "Veinte poemas de amor y una canción desesperada”. España: Universidad Cardenal - Herrera - Depto. de Comunicación CEU San Pablo, 2006.

\section{Residencia EN LA TIERRA}

Castillo-Berchenko, Adriana. "Pablo Neruda y el poema en prosa. De Anillos (1926) a Residencia en la tierra (1935)". Escritural 1 (2009): 53-63.

Concha, Jaime. "Tiempo y recuerdo en Residencia en la tierra". Nerudiana 1 (2006): 2-7. “Tiempo y recuerdo en Residencia en la tierra". Escritural 1 (2009): 64-72.

Géal, Francois. "La exacerbación del sujeto simbolista en la primera Residencia: el ejemplo del autorretrato a-referencial de 'Débil del alba'". Actas Congreso Internacional Pablo Neruda. Chile: Universidad de Chile, Facultad de Filosofía y Humanidades, 2007. 61-74.

Montesinos Gilbert, Toni. "Poesía de la soledad en viaje: Residencia en la tierra". El extramundi y los papeles de Iria Flavia XIII (2005): 55-73.

1 La presente bibliografía incluye preferentemente material bibliográfico que se encuentra en la actual colección de la Biblioteca especializada de la Fundación Pablo Neruda. Se han incluido, además, algunas otras fuentes, para complementarla. Debemos advertir, por lo tanto, que esta bibliografía no es exhaustiva. Preparada por Edmundo Olivares y editada por Elena Marfull. 
Sara, Marie-Laure. "El Palimpsesto Simbolista de Residencia en la Tierra”. Trabajo presentado en el Congreso Internacional del Centenario de Pablo Neruda. París, Francia: Universidad de Poitiers, 2007.

Sara, Marie-Laure. "El palimpsesto simbolista de Residencia en la tierra". Escritural 1 (2009): 224-233.

\section{Canto general}

Casimiro, Dominique. "Sublimación, virtualidad del sonido y voz poemática en Canto general (1950), de Pablo Neruda”. Nerudiana 3 (2007): 14-16.

Concha, Jaime. "A orillas de Canto General". Actas Congreso Internacional Pablo Neruda. Chile: Universidad de Chile, Facultad de Filosofía y Humanidades, 2007. 369-391.

Rojas, Waldo. "Una lectura de "Juventud”: ¿Ecos de Residencia en pleno corazón de Canto General?" Escritural 1 (2009): 39-52.

Sarmiento, Oscar. "Política del espectro en 'Alturas de Macchu Picchu". Actas Congreso Internacional Pablo Neruda. Chile: Universidad de Chile, Facultad de Filosofía y Humanidades, 2007. 91-98.

\section{Odas elementales}

Catalán, Pablo. "Emisor, objeto y receptor en las Odas elementales de Pablo Neruda. Tercer libro de las Odas, Navegaciones y Regresos". Actas Congreso Internacional Pablo Neruda. Chile: Universidad de Chile, Facultad de Filosofía y Humanidades, 2007. 163-178.

"Emisor, objeto y receptor en las Odas elementales de Pablo Neruda". Escritural 1 (2009): 73-85.

Cuneo, Ana María. “Arte poética en Odas elementales de Pablo Neruda”. Actas Congreso Internacional Pablo Neruda. Chile: Universidad de Chile, Facultad de Filosofía y Humanidades, 2007. 139-150.

\section{Estravagario}

Castellano Girón, Hernán. “Estravagario: 50 años en Isla Negra”. Nerudiana 6 (2008): 32-33.

Reinoso Canelo, Sara. "Estravagario: La posmodernidad nerudiana en clave carnavalesca". Nerudiana 3 (2007): 10-14.

\section{FIN DE MUNDO}

Cariz, Melina. "Neruda posmoderno 1957-1973 (II): La dimensión apocalíptica en "Fin de mundo" (1969)". Nerudiana 6 (2008): 10-12. 


\section{ESTUDIOS GENERALES}

Concha, Jaime. En torno a un Centenario: cuatro estudios sobre Pablo Neruda. Italia: Andrea Lippolis, 2006.

Dawes, Greg. "Neruda ante la "New Criticism" anglosajona". Nerudiana 7 (2006): 16-19. Verses against the Darkness: Pablo Neruda's poetry and politics. Lewisburg, Estados Unidos: Bucknell University Press, 2006.

Daydi-Tolson, Santiago. "Bodegones y odas". Actas Congreso Internacional Pablo Neruda. Chile: Universidad de Chile, Facultad de Filosofía y Humanidades, 2007. 151-161.

Fischer, María Luisa. Neruda: Construcción y legados de una figura cultural. Santiago, Chile: Editorial Universitaria, 2008.

"Ficciones de Neruda, reflexiones a partir del personaje narrativo". Escritural 1 (2009): 134-142.

"Navegaciones y anclajes del antinerudismo". Nerudiana 7 (2009): 30-32.

Holas, Sergio. "La impureza: sus implicaciones en la poesía y las colecciones de Pablo Neruda”. Signos 38 (57) (2005): 91-100.

"Deseo de la contigüidad e impureza en la poesía de Pablo Neruda". Actas Congreso

Internacional Pablo Neruda. Chile: Universidad de Chile, Facultad de Filosofía y Humanidades, 2007. 311-320.

Jofré, Manuel. "El primer texto de Neftalí Reyes". Actas Congreso Internacional Pablo

Neruda. Chile: Universidad de Chile, Facultad de Filosofía y Humanidades, 2007. 357-368. "La dimensión científica en la obra de Neruda". Nerudiana 4 (2007): 18-23. "El último poema: Hastaciel”. Nerudiana 5 (2008): 20-21.

“"Hastaciel”, el último poema de Neruda”. Escritural 1 (2009): 255-263.

Madrigal, Luis Íñigo. "Neruda y la poesía chilena de la primera mitad del siglo XX”. Escritural 1 (2009): 25-29.

Marzal, Carlos. "Neruda: el Poema de lo Real". Cuadernos Hispanoamericanos 711 (2009): 17-31.

Melis, Antonio. "Pablo Neruda y las piedras de Europa". Escritural 1 (2009): 152-160.

Millares, Selena. "El Poeta y la Muerte: Hastaciel de Neruda". Nerudiana 6 (2008): 23-26.

Neruda: El fuego y la fragua. España: Editorial Universidad de Salamanca, 2008.

"Pablo Neruda en el taller de la escritura: homenajes y profanaciones". Escritural 1 (2009): 217-223.

Moltedo, Ennio. Neruda: poeta del Cerro Florida. Valparaíso: Editorial Universidad de Valparaíso, 2008.

Montes, Hugo. Macchu Picchu en la poesía de Pablo Neruda. $4^{\mathrm{a}}$ ed. Santiago: Editorial Zig-Zag, 2009.

Moreno, Fernando. "Los ríos arteriales". Actas Congreso Internacional Pablo Neruda. Chile: Universidad de Chile, Facultad de Filosofía y Humanidades, 2007. 99-106.

"Neruda en Poitiers". Escritural 1 (2009): 11-12. 
Müller, Brenda. "Neruda: la mujer en La espada encendida". Nerudiana 6 (2008): 15-17. “Neruda 1969: Aún. Un mundo no leído aún en sus totales”. Nerudiana 8 (2009): 4-6.

Oses, Darío. “Algo sobre la naturaleza y su representación en Pablo Neruda”. Nerudiana 8 (2009): 15-17.

"Pablo Neruda: El vate que celebró llorando la modernidad". Nuevamérica 24 (2009): 64-69.

Pereira, Sergio. "Los códigos expresionistas en Fulgor y muerte de Joaquín Murieta, de Pablo Neruda”. Actas Congreso Internacional Pablo Neruda. Chile: Universidad de Chile, Facultad de Filosofía y Humanidades, 2007. 321-334.

Pino, Mirian. "Pablo Neruda y la dimensión ecológica en El libro de las preguntas (1974)". Actas Congreso Internacional Pablo Neruda. Chile: Universidad de Chile, Facultad de Filosofía y Humanidades, 2007. 299-307.

Piñones, Julio. "Significantes temporales nerudianos en la semiótica de la cultura". Actas Congreso Internacional Pablo Neruda. Chile: Universidad de Chile, Facultad de Filosofía y Humanidades, 2007. 291-298.

"La tentativa escritural del infinito Neruda". Escritural 1 (2009): 234 - 239.

Prado, Traverso Marcela. "Jardín de invierno: la materia trascendente". Escritural 1 (2009): 249-254.

Predmore, Michael. "Imágenes y visiones apocalípticas en Residencia en la tierra y Canto general: de Revelación a Revolución en la poesía". Actas Congreso Internacional Pablo Neruda. Chile: Universidad de Chile, Facultad de Filosofía y Humanidades, 2007. 75-87.

Rodríguez P., Osvaldo. "La interrogante como expresión poética de la incertidumbre nerudiana". ALPHA. Revista de Artes, Letras y Filosofia 21 (2005): 87-101.

Rojo, Grínor. "La tradición de la poesía de las ruinas: a propósito de Alturas de Macchu Picchu". Actas Congreso Internacional Pablo Neruda. Chile: Universidad de Chile, Facultad de Filosofía y Humanidades, 2007. 107-117.

Rubilar S., Luis. "Pablo Neruda: el imaginario que transformó la identidad de Neftalí Reyes". Actas Congreso Internacional Pablo Neruda. Chile: Universidad de Chile, Facultad de Filosofía y Humanidades, 2007. 51-58.

"Poesía y Derechos Humanos: el legado de Neruda". Ensayos para la Reconciliación. Derechos Humanos, fundamento de la Convivencia: 2o. Concurso nacional de Ensayos. Premio Profesor Jorge Millas. Santiago, Chile: Corporación Nacional de Reparación y Reconciliación; SECH, 2009. 117-159.

Salgado, María A. "Una casa en la arena: legado poético de un Neruda comprometido". Escritural 1 (2009): 143-151.

San Francisco, Alejandro. "Pablo Neruda, poeta de la revolución americana". Actas Congreso Internacional Pablo Neruda. Chile: Universidad de Chile, Facultad de Filosofía y Humanidades, 2007. 335-353.

Sara, Marie-Laure. "Neruda póstumo para lectores intranquilos". Nerudiana 5 (2008): 10-12.

Sicard, Alain. "Cinco desterrados y un sobreviviente o los embajadores de la profundidad". Nerudiana 1 (2006): 11-14.

"Neruda: La poética de los objetos". Nerudiana 2 (2006): 8-14. 
"El yo nerudiano". Actas Congreso Internacional Pablo Neruda. Chile: Universidad de Chile, Facultad de Filosofía y Humanidades, 2007. 27-40.

"Dossier: Neruda posmoderno. Chivilcoy, transeúnte de la modernidad". Nerudiana 5 (2008): 7-9.

"De la envidia y sus alrededores". Nerudiana 7 (2009): 4-9.

"De la envidia y sus alrededores". Escritural 1 (2009): 384-396.

Urbina, Leandro. "Neruda y la nación criolla". Actas Congreso Internacional Pablo Neruda. Chile: Universidad de Chile, Facultad de Filosofía y Humanidades, 2007. 127-136.

Wilson, Jason. A companion to Pablo Neruda. Evaluating Neruda's poetry. U.S.A.: Editorial Tamesis, 2008.

\section{ESTUDIOS BIOGRÁFICOS Y AFINES}

Alberti, Aitana. Inquilinos de la soledad. La Habana: Ediciones La Unión, 2006.

Álvarez-Rubio, Pilar. "Memorial de Isla Negra, épica personal de Neruda". Escritural 1 (2009): 104-109.

Amaro, Lorena. "Las vidas del poeta". Actas Congreso Internacional Pablo Neruda. Chile: Universidad de Chile, Facultad de Filosofía y Humanidades, 2007. 41-49.

Antolín, Marco. "Referencialidad de Pablo Neruda en los Estados Unidos: asociación de imágenes, emotividad y papel del poeta en su contexto social". Actas Congreso Internacional Pablo Neruda. Chile: Universidad de Chile, Facultad de Filosofía y Humanidades, 2007. 269-277.

Augier, Angel. "1942: Neruda en Cuba”. Nerudiana 2 (2006): 22-24.

Barraza, Fernando. "Neruda 1969: Un viaje al corazón de Isla Negra”. Nerudiana 8 (2009): 23-25.

Barría B., Audénico. "Napolitano visitó casa de Neruda en Isla Negra: mandatario ayudó al poeta chileno a publicar el libro 'Los versos del capitán”". El Mercurio. 17 mar. 2008: C-6.

Barrientos Tecún, Dante. "Comiendo en Hungría (Neruda, Asturias, 1969)”. Escritural 1 (2009): 287-297.

Barros, Cristián. "Neruda en Birmania: las puertas de Oriente”. El Mercurio. 14 jul. 2006: RL-7.

Bottiglieri, Incola. Las casas de Neruda. Punta Arenas, Chile: F.S. Editorial, 2009.

Bulnes, Kittin. "Neruda y Fornasetti”. Nerudiana 6 (2008): 4-5.

Carcedo, Diego. Neruda y el Barco de la Esperanza: La historia del salvamento de miles de exiliados españoles de la Guerra Civil. Madrid: Ediciones Temas de Hoy, 2006.

Cárdenas, María Teresa. "Roberto Ampuero: cita con el Neruda íntimo". El Mercurio. 24 ago. 2008: E-19.

Cardone, Inés María. "Descubierto el rostro de Malva Marina, la única hija del poeta". Elcultural. es. 14 de octubre de 2004. http://www.elcultural.es/version_papel/LETRAS/10418/ El_secreto_mejor_guardado_de_Neruda.

"Laura "Lala" Arrué. 1907-1986". Nerudiana 4 (2007): 6-7. 
Casas / Houses: NERUDA. Santiago: Editorial Pehuén, 2008.

Castanedo Pfeiffer, Gunther. "Olga Margarita Burgos, la dentista que surgió del frío”. Cantabria Dental 5 (2007): 6-11.

"Un centenario imprevisto. Olga Margarita Burgos. 1907-1998". Nerudiana 4 (2007): 14-17.

“El Poeta y el Zar Rojo. Pablo Neruda y José Stalin". Pablo Neruda en Santander:

Primer Encuentro. Santander: Edición Obra Social Caja Cantabria, 2008. 57-67.

"El Winnipeg sin Neruda". Nerudiana 8 (2009): 12-14.

Castellano Girón, Hernán. "Isla Negra: [Poema]”. Nerudiana 6 (2006): 32.

Catálogo: "Amor al mar": exposición de caracolas de la colección Pablo Neruda donadas a la Universidad de Chile. Madrid: TF Artes Gráficas, 2009.

Cepeda Vargas, Gloria. "Pablo y la Mujer”. Convergencia 37 (2005): 331-343.

Chilenos del Bicentenario. Los hombres y las mujeres que cambiaron nuestra historia: Pablo Neruda / Roberto Matta. Chile: Edición de Instituciones Santo Tomás; El Mercurio, 2007.

Cipolloni, Marco. "Neruda sobre Neruda. Las fuentes nerudianas de Il postino, entre neorrealismo y guerra fría". Escritural 1 (2009): 121-133.

Correspondencia Neruda-Eandi. Buenos Aires: Ediciones Corregidor, 2008.

Cotera, Alejandro. "Neruda y la resistencia a los antibióticos". Nerudiana 8 (2009): 18-21.

Dannemann, Manuel. "Los otros grandes amores de Neruda: Joyas Bibliográficas del Archivo Central de la Universidad de Chile". Boletín Académico Universidad de Chile (2007): 78-80.

Délano, Poli y Julio Gálvez. "Délano-Neruda: Dos notas sobre una vieja amistad”. Nerudiana 4 (2007): 10-12.

Díaz-Cid, César. "La memoria del cisne: confesión del yo nerudiano". Escritural 1 (2009): 97-103.

Díaz Soto, Mireya. “A 35 años de su muerte: Las casas de Pablo Neruda: el mundo construido por Neruda”. Revista Vivienda y Decoración. El Mercurio. 20 sep. 2008: 34-43.

Domínguez, Delia. "Pablo Neruda en familia: hora de nacer en las estrellas de agua". El Mercurio. 06 jul. 2008: E-21.

"El sueño de Cantalao. Resumen de un coloquio sobre el tema". Cuadernos Fundación Pablo Neruda 56 (2005): 8-15.

“El sueño de Cantalao: Segunda Parte”. Cuadernos Fundación Pablo Neruda 57 (2005): 50-57.

“El sueño de Cantalao: (Tercera parte)". Cuadernos Fundación Pablo Neruda 58 (2006): 22-23.

"El sueño de Cantalao: (Cuarta parte)". Cuadernos Fundación Pablo Neruda 59 (2006): 48-53.

"El sueño de Cantalao: (Quinta parte y final)". Cuadernos Fundación Pablo Neruda 60 (2007): 46-57.

Ferrer, Jaime. "La Misión de Amor de Pablo Neruda. El Winnipeg, un Poema que Surcó Mares". Cuadernos Hispanoamericanos 711 (2009): 69-74.

Gálvez Barraza, Julio. "El conflicto que amenazó la misión del Winnipeg". Nerudiana 8 (2009): 10-12. “¿Qué fue del Winnipeg?” Cuadernos Hispanoamericanos 711 (2009): 109-122. 
García Méndez, Javier. "No podía sino llamarse Pablo o la autonominación como fundación". Escritural 1 (2009): 86-96.

García-Tello, María Luisa. Mujeres de Neruda - Breve Crónica. Chile: Impresos Libra, 2006. Gattai, Zelia. "Mi amigo y compadre Pablo Neruda". Nerudiana 2 (2006): 5-7.

"Giorgio Napolitano: Amigo de Neruda, nuevo Presidente italiano. El ex-comunista le ayudó a financiar "Los versos del capitán" y protegió al poeta durante su estadía en ese país". El Mercurio. 11 may. 2006: A-4.

González Colville, Jaime. "Partida de bautismo de la madre de Neruda”. Nerudiana 1 (2006): 21. Gras, Dunia. "Neruda, persona y personaje”. Escritural 1 (2009): 110-120.

Guerrero, Pedro Pablo. "Hallazgo epistolario 1962-1973: la reveladora correspondencia entre Pablo Neruda y Jorge Edwards”. Revista de Libros. El Mercurio. 18 nov. 2007: E-19.

“A 104 años del nacimiento de Neruda "Álbum de Isla Negra”. Hallazgo: el libro manuscrito que Pablo Neruda le dedicó a Alicia Urrutia”. El Mercurio. 06 jul. 2008: E-19-20.

Gumucio, Rafael. "El sueño de la Isla Propia (Una visita a Isla Negra)". Revista de Libros. El Mercurio. 23 dic. 2005: 12.

"Neruda y el hielo". Nerudiana 2 (2006): 32.

Gutiérrez Revuelta, Pedro. "Neruda, mon amour". Nerudiana 6 (2008): 13-14.

Hachtroufi, Fariba. Le Chili, sur les traces de Neruda. París: Seuil, 2005.

H. L. "Volodia y Pablo. El comienzo de una larga amistad". Nerudiana 5 (2008): 2-5.

Herrera, Edmundo. "Septiembre de 1973: una primavera dolorosa”. Nerudiana 8 (2009): 27-28.

Jofré, Manuel. "La identidad en el nombrar: Neftalí/Neruda y su madre”. Nomadias (2005): 207-218.

Lastra, Pedro. "Nerudiana personal”. Nerudiana 7 (2009): 40.

“1972: Neruda y María”. Nerudiana 8 (2009): 25-27.

Latorre U., Marina. “Mi amigo Pablo Neruda”. Portal 29 (2008): 5-7.

Lennon Z., Maureen. "Inédita muestra revive la amistad de Neruda y Picasso: Son 16 litografías del pintor malagueño que ilustraron el poema "Toro", del premio Nobel de Literatura". El Mercurio. 11 may. 2007: A-10.

Loyola, Hernán. "Las caracolas de Neruda". Nerudiana 2 (2006): 1-2.

Neruda: la biografia literaria. I.- La formación de un poeta. (1904-1932). Santiago: Seix Barral. Biblioteca Breve; Editorial Planeta Chilena S.A., 2006.

"La CIA contra Neruda (1963)". Nerudiana 3 (2007): 22-23.

"Neruda y la Universidad de Chile". Actas Congreso Internacional Pablo Neruda.

Chile: Universidad de Chile, Facultad de Filosofía y Humanidades, 2007. 411-423.

"Neruda posmoderno". Pablo Neruda en Santander: Primer Encuentro. Santander: Edición Obra Social Caja Cantabria, 2008. 11-27.

"Pablo y Alicia. Hallazgo: el libro manuscrito que Pablo Neruda le dedicó a Alicia Urrutia”. El Mercurio. 06 jul. 2008: E-19.

Magni, Barbara y Fabio Rodríguez Amaya. "Pablo Neruda 1950-1952: el exilio italiano". Escritural 1 (2009): 188-202. 
Navarrete Cáceres, Carlos. "Pablo Neruda en Guatemala: la primera estancia: 1941". Actas Congreso Internacional Pablo Neruda. Chile: Universidad de Chile, Facultad de Filosofía y Humanidades, 2007. 219-268.

Neira, Julio. "España en el corazón de Pablo Neruda". Pablo Neruda en Santander: Primer Encuentro. Santander: Edición Obra Social Caja Cantabria, 2008. 29-42.

"Neruda en los 20". Cuadernos Fundación Pablo Neruda 61 (2008): 83-85.

Obregón, Osvaldo. "Pablo Neruda, "aprendiz de teatrero": el mito de Murieta". Escritural 1 (2009): 203-212.

Olivares, Edmundo. "Pequeña historia de un gran epistolario". Cuadernos Fundación Pablo Neruda 57 (2005): 120-125.

“Temuco 1908: Una ciudad... un niño... un incendio". Nerudiana 3 (2007): 17-19. "Neruda: 1959: Ventura y desventura de una carta". Nerudiana 8 (2009): 15.

Oses, Darío. "Memorial de la costa: en la prehistoria del litoral". Cuadernos Fundación Pablo Neruda 58 (2006): 24-25.

Ostria, Mauricio. "Visión nerudiana del desierto nortino". Actas Congreso Internacional Pablo Neruda. Chile: Universidad de Chile, Facultad de Filosofía y Humanidades, 2007. 281-289.

"Otro amor de Neruda". El Mercurio. 30 mar. 2008: E-29.

Paredes, Alberto. "El último Neruda: piano e malinconico". Escritural 1 (2009): 240-248.

Peña, Cristóbal. "Pacto de amor traicionado: El día en que Pablo Neruda y Delia del Carril terminaron con una relación de veinte años”. Reportajes. La Tercera. 20 feb. 2005: 17.

Pey, Víctor. “Cómo me embarqué en el Winnipeg”. Nerudiana 8 (2009): 7-10.

Quezada Vergara, Abraham, comp. "Luces y sombras de Neruda: la antesala del premio Nobel: Neruda en Oxford”. El Mercurio. 28 sep. 2008: E-23.

Quintana Tejera, Luis. "La poesía testimonio de Pablo Neruda. Canto al amigo poeta y poema a una ciudad valerosa". Escritural 1 (2009): 166-187.

Reyes, Bernardo. El enigma de Malva Marina: la hija de Pablo Neruda. Santiago: RIL Editores, 2007.

“La residencia en Argüelles”. El Mercurio. 06 jul. 2008: E-21.

Risques, Manuel y Ricard Vinyes. "El exilio circular". Cuadernos Hispanoamericanos 711 (2009): 65-68.

Rivas, Francisco. "Pablo Neruda, su vínculo con el mar”. Escritural 1 (2009): 264-269.

Robertson, Enrique. "La hazaña del Winnipeg: furiosos ecos en Madrid”. Nerudiana 8 (2009): 14.

Rodríguez Bustos, Gabriel. Neftalí, el niño de Parral. Chile: Pentagrama Editores, 2007.

Rojas, Gonzalo. “Winnipeg y más Winnipeg”. Cuadernos Hispanoamericanos 711 (2009): 7-10.

Rojas, Waldo. "Neruda en Potiers (12.07.2004)". Nerudiana 3 (2007): 23.

“Testimonio: Conocer (¿en persona?) a Neruda”. Nerudiana 5 (2008): 22 - 23.

Rojas V., Constanza. "En librerías. 'Humor, amistades y anécdotas de Pablo Neruda"”. El Mercurio. 27 sep. 2008: A-24.

Rosevinge, Teresa. "El barco de los pintores". Cuadernos Hispanoamericanos 711 (2009): 35-39. 
Rovira, José Carlos. Pablo Neruda. Álbum. Madrid: Publicaciones de la Residencia de Estudiantes, 2007. "Viajero por el mundo, regresos y memorias". Escritural 1 (2009): 13-24.

Rovira, José Carlos, et al. "Imágenes de una vida”. Cuadernos Fundación Pablo Neruda 61 (2008): 107-110.

Rubio R., Inés. “Con Neruda en Budapest (1965)”. Nerudiana 8 (2009): 22-23.

Scandro, Edith. "Con Neruda en 1958 - Mi encuentro con Neruda". Nerudiana 8 (2009): 21-22.

Schidlowsky, David. “Años '30: Neruda y los Congresos de Escritores por la Defensa de la Cultura”. Nerudiana 2 (2006): 17-20.

"Enigmas de Maruca Reyes". El Mercurio. 28 sep. 2008: E-23.

Las furias y las penas. Pablo Neruda y su tiempo. Santiago: RIL Editores, 2008.

Stavans, Ilán. "Publicación: Una amplia biografía del Premio Nobel chileno". El Mercurio. 10 may. 2009: E-15.

Teitelboim, Volodia. "El poeta que donaba bibliotecas". Mapocho. Revista de Humanidades. 1er. Semestre. 57 (2005): 417-424.

"El burlador del Parnaso". Actas Congreso Internacional Pablo Neruda. Chile: Universidad de Chile, Facultad de Filosofía y Humanidades, 2007. 393-410.

Unterhofer, Simone. Casa-Museo di Pablo Neruda a Isla Negra: Tesi di Laurea in Museologia. Firenze: Università degli Studi di Firenze - Facoltà di Lettere e Filosofia, 2006.

Valdovinos, Mario. "La hija de Pablo Neruda: El enigma de Malva Marina". El Mercurio. 25 nov. 2007: E-24

"Neruda en año de penurias: [Recuerdos de los años Post-Golpe Militar 1973]". Nerudiana 6 (2008): 27-28.

Zurita, Raúl. "El Poema Imperecedero: sobre el Winnipeg de Neruda". Cuadernos Hispanoamericanos 711 (2009): 11-16.

\section{NERUDA TRADUCTOR}

Capraroiu, Gabriela. "Neruda traductor: 44 poetas rumanos (1967)". Nerudiana 5 (2008): 15-17. "Neruda traductor: el ejemplo rumano". Escritural 1 (2009): 375-383.

\section{RELACIONES LITERARIAS}

Castanedo Pfeiffer, Gunther. Pablo Neruda y Don Antonio Machado. Santander: Voces del Cotero, 2005.

Un triángulo literario: José María de Cossío, Miguel Hernández, Pablo Neruda. Santander: Voces del Cotero, 2005.

"Dos Premios Nobel frente a frente: Pablo Neruda y Vicente Aleixandre". Ateneo. Revista Científica, Literaria y Artística XIX-XX (2008): 61-67. 
"Larrea / Neruda: Itinerario de una enemistad". Nerudiana 7 (2009): 21-23.

Castellano Girón, Hernán. “Antipoetas: Huidobro, Neruda, Parra”. Nerudiana 1 (2006): 1, 8-11.

Castillo Granada, Alvaro. De cuando Pablo Neruda plagió a Miguel Ángel Macau. Bogotá: Ediciones San Librario, 2008.

Castillo Letelier, Miguel Angel. "Neruda y Paz: conjunciones y disyunciones". Actas Congreso Internacional Pablo Neruda. Chile: Universidad de Chile, Facultad de Filosofía y Humanidades, 2007. 211-216.

Dawes, Greg. "Neruda y Vallejo ante la vanguardia". Nerudiana 6 (2008): 6-9.

D. O. M. "Rubén Darío y Pablo Neruda". Cuadernos Fundación Pablo Neruda 60 (2007): 22-27.

España en el corazón. Delia en el corazón. Santiago: Edición Centro Cultural de España, 2005.

García Gutiérrez, Rosa. "Neruda y Lorca al alimón: texto y contexto de Paloma por dentro". Escritural 1 (2009): 319-341.

Inda, Enrique. "Mario Toral y Pablo Neruda. Diálogo entre poesía y arte". Cuadernos Fundación Pablo Neruda 61 (2008): 98-104.

Isausti, Gabriel. "La atalaya del mundo: Neruda y Huidobro en las alturas". Escritural 1 (2009): 298-318.

Jofré, Alvaro Salvador. "Pablo Neruda, Federico García Lorca y el surrealismo hispánico". Actas Congreso Internacional Pablo Neruda. Chile: Universidad de Chile, Facultad de Filosofía y Humanidades, 2007. 201-210.

Lagunero, Teodulfo. Una vida entre poetas. De Pablo Neruda a Antonio Gala. España: La esfera de los libros, 2006.

Lennon Z., Maureen. “'Fulgor y muerte de Joaquín Murieta', de Pablo Neruda y Sergio Ortega: Isabel Allende en DVD de ópera chilena". El Mercurio. 20 dic. 2006: A-8.

"Publican epistolario entre Neruda y Jorge Edwards". El Mercurio. 05 may. 2008: A-11.

López García, José Ramón. "Las Travesías del Exilio de Arturo Serrano Plaja”. Cuadernos Hispanoamericanos 711 (2009): 97-107.

Loyola, Hernán. "Lorca y Neruda en Buenos Aires (1933-1934)". Vivir es ver volver: Studi in onore di Gabriele Morelli. Bérgamo: Sestante Edizioni, 2009. 345-362.

Maldonado Araque, Francisco Javier. "Panero y Neruda: Canto Personal vs. Canto General: (Una lucha poética y política en tiempos de posguerra)". Cuadernos Hispanoamericanos 692 (2008): 93-115.

Miranda, Paula. "Configuraciones de la identidad nacional en Canto general y en Carta magna de Chile, de Pablo de Rokha". Actas Congreso Internacional Pablo Neruda. Chile: Universidad de Chile, Facultad de Filosofía y Humanidades, 2007. 181-200.

Mistral, Gabriela. "Recado sobre Pablo Neruda". Nerudiana 1 (2006): 19-20.

Ortiz de Rozas, Marilú. "Carreño y Neruda: una amistad poética y plástica". Nerudiana 6 (2008): 20-22.

"Duelo literario entre nerudianos". El Mercurio. 27 nov. 2008: A-13.

Oses, Darío. "Otra historia de la infamia: Sobre el libro de Volodia Teitelboim: «La guerra interna»". Cuadernos Fundación Pablo Neruda 58 (2006): 118-119. 
Promis, José. "Primeras andanzas de Cayetano Brulé”. El Mercurio. 28 sep. 2008: E-22.

Quezada, Jaime. "Neruda en el Valle de Elqui y otros encuentros con Gabriela Mistral". Cuadernos Fundación Pablo Neruda 57 (2005): 6-9.

Quezada Vergara, Abraham (comp.). Cartas que romperemos de inmediato y recordaremos siempre: correspondencia entre Pablo Neruda y Jorge Edwards. Santiago: Editorial Alfaguara, 2008.

Robertson, Enrique. "Picasso y Neruda. El rostro del poeta combatiente por la paz". Escritural 1 (2009): 213-216.

Robertson, Enrique y Alain Sicard. "El antinerudismo iconográfico de Javier Marías". Nerudiana 7 (2009): 10-11.

Rodríguez Céspedes, Alvaro. “Agonía, presencia y hermetismo en la poética de Pablo Neruda y Walt Whitman”. Escritural 1 (2009): 270-286.

Rojo, Grínor. "Neruda, Pacheco, Gelman, Belli y la tradición de la poesía latinoamericana moderna". Revista de Libros, El Mercurio. 15 abr. 2007: 17.

Salerno, Nicolás. “«El caso Neruda», de Roberto Ampuero”. Nerudiana 6 (2008): 38-39.

Serna Arnaiz, Mercedes. "Martí y Neruda Unidos por la República Española". Cuadernos Hispanoamericanos 711 (2009): 87-96.

Skármeta, Antonio. Skármeta-Neruda, La magia in azione. Parma: Ugo Guanda Editore, 2006.

Stanton, Anthony. "Pablo Neruda y Octavio Paz: encuentros y desencuentros". Escritural 1 (2009): 357-374.

Stauder, Thomas. "La amistad entre Pablo Neruda y Miguel Hernández". Escritural 1 (2009): 342-356.

Téllez, Juan José. "Rafael Alberti, entre las Totoras de El Totoral”. Cuadernos Hispanoamericanos 707 (2009): 45-56.

Valdovinos, Mario. "Huellas de Rimbaud en Neruda". Nerudiana 3 (2007): 20-22.

"Cartas que recordaremos siempre: correspondencia entre Pablo Neruda y Jorge Edwards". Revista de Libros, El Mercurio. 11 may. 2008: E-23.

"El antinerudismo delirante: Pablo de Rokha". Nerudiana 7 (2009): 13-15.

\section{HOMENAJES}

“A 36 años de la muerte de Neruda”. Nerudiana 8 (2009): 30.

Bertrand, Sara. "Escultura. Concurso Internacional: un memorial para Neruda en Isla Negra". El Mercurio. 30 sep. 2007: E-27

Caistor, Nick. "Obituaries: Robert Pring-Mill. Academic and expert on Latin American revolutionary songs, literature and poetry". Guardian.co.uk. 17 de octubre de 2005. http:// www.guardian.co.uk/news/2005/oct/17/guardianobituaries.highereducation.

Campos, Marcos Antonio. “Conversación imaginaria con Pablo Neruda”. Nerudiana 1 (2006): 22.

Campillo, María. "Chile en el Corazón. Los Escritores del Florida y Pablo Neruda”. Cuadernos Hispanoamericanos 711 (2009): 77-85. 
"Concurso nacional e internacional: Crearán monumento a Neruda [Cantalao]". El Mercurio. 18 dic. 2006: A-10.

Folch C., Francisca. "Cuerpos, desnudos y los pájaros de Neruda". El Mercurio. 01 jun. 2006: A-9.

Freire, Maynor. "Macchu Picchu, donde mora el alma americana". Actas Congreso Internacional Pablo Neruda. Chile: Universidad de Chile, Facultad de Filosofía y Humanidades, 2007. 119-125.

"Poesía de Neruda sigue viva en su Isla Negra". Escritural 1 (2009): 161-165.

Guirado, Kristel. Los juguetes más grandes: Homenaje al poeta Pablo Neruda. Venezuela: Edición de COFAE, 2006.

Gómez Bravo, Andrés. "La guerrilla por el legado de Neruda". La Tercera. 21 ago. 2005: 29.

Jofré, Manuel. "Réquiem pour revés assassinéss: hommage a Pablo Neruda". Anales de la Universidad de Chile. Sexta serie, 17 (2005): 127.

Loyola, Hernán. "Susana Baca canta poemas de Neruda". Nerudiana 6 (2008): 39.

"Discurso de incorporación a la Academia Chilena de la Lengua como miembro correspondiente en Cerdeña (Italia) el 30 de noviembre de 2009”. Inserto a Nerudiana 8 (2009): 20-28.

"Más de 300 voces en el Canto general de Neruda: «Estarán el coro más grande de Europa, Los Jaivas y el Coro de la U. de Chile»". El Mercurio. 13 ago. 2007: A-8.

Omaggio a Pablo Neruda. Centenario 1904 - 2004: Imparerai di nuovo ad esser stella. Roma: Provincia di Roma, 2005.

Pablo Neruda en el corazón de México: En el Centenario de su Nacimiento. México: UNAM, Instituto de Investigaciones Bibliográficas, 2006.

Pablo Neruda en Santander: Primer Encuentro. Santander: Edición Obra Social Caja Cantabria, 2008.

Pablo Neruda: De la poèsie à la lutte. París: EPM, SWProductionS, 2006.

Rafide, Matías, ed. et al. Poetas del Maule: antología poética para el Bicentenario. Talca: Edición Universidad de Talca, 2007.

Sánchez, Matilde. "Pablo Neruda: versos para el amigo poeta y camarada". N. Revista de cultura. 07 de julio de 2008. http://edant.revistaenie.clarin.com/notas/2008/07/07/01710163.html.

Sicard, Alain. "Manuel Toledo, Fernando Moreno: Adioses. Homenajes póstumos a: Robert Prig-Mill, Saúl Yurkievich”. Nerudiana 1 (2006): 27-28.

Toral, Mario. "«El habitante de esta casa fue un hombre enamorado...»: [Palabras de Toral al recibir el Premio Medalla de Honor 2007]". Cuadernos Fundación Pablo Neruda 61 (2008): 105 - 106.

Zía, Lisardo. "Retrato de un Poeta: [poema dedicado a Neruda]". Nerudiana 6 (2008): 40. 


\section{ENTREVISTAS}

Guerrero, Pedro Pablo. "Entrevista a Hernán Loyola. Cuando Neruda refunda su poesía: «La formación de un poeta (1904-1923)»” . Revista de Libros. El Mercurio. 14 jul. 2006: 6-7.

"Entrevista a mítica agente literaria Carmen Balcells: «Yo no soy de verdad, soy un personaje proyectado»". El Mercurio. 29 mar. 2009: E-2-3.

Matus, Alvaro. "«Neruda se merece las disculpas de Cuba»: Entrevista a Hernán Loyola, biógrafo del poeta”. El Mercurio. 25 mar. 2007: E-2-3.

Muñoz H., Juan Antonio. "Entrevista exclusiva a soprano chilena: Cristina Gallardo-Domâs será Matilde Urrutia en el estreno mundial de «Il Postino»”. El Mercurio. 18 mar. 2007: E-10-11.

Rojas V., Constanza. "Entrevista a Ilan Stavans: «Los grandes clásicos están llenos de basura»”. El Mercurio. 13 may. 2009: A-9.

\section{RESEÑAS}

Castanedo Pfeiffer, Gunther. "Reseña crítica sobre el libro de Edmundo Olivares Pablo NerudaHéctor Eandi: Itinerario de una amistad”. Nerudiana 5 (2008): 28-29.

"Cuaderno. Desde esta semana en quioscos: La Fundación Neruda lanza nueva revista". El Mercurio. 30 nov. 2008: E-4.

Dawes, Greg. "Reseña crítica a David Schidlowsky: Las furias y las penas". Nerudiana 3 (2007): 24-26.

"Reseña sobre el libro: 'Neruda: Construcción y legados de una figura cultural', de María Luisa Fischer”. Nerudiana 7 (2009): 37-39.

Duery A., Lilian. "Nuevo Libro: Neruda se oculta en sus caracolas. Las piezas que adornan esta obra fueron elegidas por la importancia que les dio el poeta en sus poemas y en su colección". El Mercurio. 10 nov. 2006: A-14.

"En la corriente continua de la poesía: [Sobre el libro: Antología poética. Premio Pablo Neruda. 1987-2005]". Cuadernos Fundación Pablo Neruda 58 (2006): 115.

Ifland, James. "Reseña crítica a Greg Dawes: Verses against the darkness. Pablo Neruda. Poetry and Politics". Nerudiana 3 (2007): 26-28.

Loyola, Hernán. "Reseña crítica a Jaime Concha: En torno a un centenario. Cuatro estudios sobre Pablo Neruda”. Nerudiana 3 (2007): 28-29.

"Reseña crítica sobre el libro de David Huerta: El correo de los Narvales". Nerudiana 5 (2008): 30-31.

"Reseña crítica sobre el libro de José Carlos Rovira: Pablo Neruda. Álbum". Nerudiana 5 (2008): 29-30.

"Reseña sobre el libro: "Neruda: el fuego y la fragua", de Selena Millares". Nerudiana 6 (2008): 36-38.

Marks, Camilo. "Neruda para todos: En esta biografía, que aborda al ciudadano y al creador lírico, Loyola consigue lo que casi nadie ha logrado: atraer a los especialistas y al público general". Revista de Libros. El Mercurio. 11 ago. 2006: 3. 
"Reseña crítica sobre «Neruda. La biografía literaria», de Hernán Loyola". Nerudiana 2 (2006): 27.

Montes Capó, Cristián. "Reseña crítica al libro de Manuel Jofré: Pablo Neruda: de los Mitos y el ser Americano". Nerudiana 7 (2009): 35-37.

Oses, Darío. "Reseña crítica sobre «Neruda y el barco de la esperanza», de Diego Carcedo". Nerudiana 2 (2006): 29-30.

Pérez, Floridor. "Reseña crítica sobre el libro de Poli Délano: «Policarpo y el tío Pablo»". Nerudiana 4 (2007): 28-29.

Reseña crítica del libro: "El infinito olvido en la poética nerudiana del amor", de Luis Quintana Tejera. Revista de Libros. El Mercurio. 10 mar. 2006: 9.

Rojas, Claudio. "Reseña crítica del libro «Pablo Neruda, a passion for life», de Adam Feinstein". Nerudiana 1 (2006): 29-30.

Valdivieso, Jaime. "Reseña crítica sobre la Trilogía «Tras las huellas del poeta itinerante», de Edmundo Olivares". Nerudiana 2 (2006): 28-29.

Valdovinos, Mario. "Neruda. La biografía literaria. Hernán Loyola”. Cuadernos Fundación Pablo Neruda 59 (2006): 130-131.

"Reseña crítica sobre el libro de Bernardo Reyes «El enigma de Malva Marina»". Nerudiana 4 (2007): 30-31.

"Reseña crítica sobre el libro de Abraham Quezada: Correspondencia entre Pablo Neruda y Jorge Edwards". Nerudiana 5 (2008): 27-28.

Varas, José Miguel. "Reseña crítica sobre el libro de Julio Gálvez «Neruda y España»". Nerudiana 4 (2007): 29-30.

\section{BIBLIOGRAFÍAS}

Casimiro, Dominique. "Bibliografía reciente sobre Neruda en Francia”. Nerudiana 2 (2006): 27.

Olivares, Edmundo. "Bibliografía 1923-2004 en la Biblioteca de la Fundación Pablo Neruda". Nerudiana 2 (2006): 21.

\section{VARIOS}

Albornoz, Ana y Gabriela Corvalán. "El rol del trabajador cultural en la producción y reproducción del patrimonio intangible”. Cuadernos Fundación Pablo Neruda 58 (2006): 111-114.

Barraza Urzúa, Pedro. "Presencia de Neruda en Turquía". Cuadernos Fundación Pablo Neruda 56 (2005): 110-113.

Barrera C., Gustavo. "Malú Urriola. Premio Pablo Neruda 2006". Cuadernos Fundación Pablo Neruda 59 (2006): 54-57.

Boccanera, Jorge. "Raúl González Tuñón. Blindar la rosa”. Cuadernos Hispanoamericanos 707 (2009): 39-44. 
Casimiro, Dominique. "Neruda: la voz entre dos silencios". Nerudiana 5 (2008): 12-14.

"De buena fuente. Neruda al rojo". El Mercurio. 30 sep. 2007: E-27.

Díaz Castillo, Roberto. "Neruda en el corazón”. Actas Congreso Internacional Pablo Neruda. Chile: Universidad de Chile, Facultad de Filosofía y Humanidades, 2007. 219-225.

Ferro González, Vladimir. Con Pablo Neruda, por los Caminos de la Poesía. Cuba: Ediciones Loynaz, 2007.

Neruda y Cuba. La Habana: Editorial Arte y Literatura, 2008.

Gálvez Barraza, Julio. Home Page. 2008. http://juliogalvezbarraza.blogspot.com/2008/03/ por-obra-y-gracia-del-winnipeg.html.

García Ramos, Juan-Manuel. "Neruda después de Neruda". Cuadernos Hispanoamericanos 701 (2008): 113-126.

Garrido-Salgado, Juan. Unmoving Navigator / Navegante Inmóvil. Australia: Editores Picaro Press, 2006.

Huneeus, Carlos. La Guerra Fría Chilena. Gabriel González Videla y la Ley Maldita. Santiago: Random House-Mondadori, 2008.

Jofré, Manuel. "Cultura y literatura en la Revista Claridad". Anales de la Universidad de Chile. Sexta serie, 17 (2005): 65-99.

Lafourcade, Enrique. “¿Lo sintió como nadie? ¿Lo lloró como pocas?” El Mercurio. 08 abr. 2007: D-26.

“Los días son para crear y construir”. Cuadernos Fundación Pablo Neruda 57 (2005): 78-79.

Mandujano, Víctor M. "Murales de Alfaro Siqueiros y Xavier Guerrero en Chillán: obras de artistas mexicanos esperan refacción”. El Mercurio. 09 feb. 2008: A-19.

"En Chillán: Compleja restauración en murales de Escuela México". El Mercurio. 17 sep. 2008: A-10.

Manganelli, Sergio. "Neruda y la Primavera Infinita”. http://www.cronopios.com.br/site/ ensaios.asp? $\mathrm{id}=3518$.

Marina, José Antonio. Palabras de amor. Madrid: Temas de Hoy, 2009.

Muñoz H., Juan Antonio. “Daniel Catán: la ópera 'Il Postino’ está terminada”. El Mercurio. 20 jul. 2008: E-16.

Muro Munilla, Miguel Ángel. El Cáliz de Letras: Historia del Vino en la Literatura. Logroño: Fundación Dinastía Vivanco para la Investigación de la Cultura e Historia del Vino, 2006.

Nocera, Mauricio. Neruda 100 Anni: Addio Mondo, ti Bacio e mi Accommiato. Italia: Gallipoli, 2005 .

Novoa Fernández, Sandra. "Familia de Neruda pide US\$ 5,8 mills. a hotel que lleva el nombre del poeta: interpusieron una demanda por indemnización de perjuicios". El Mercurio. 02 dic. 2007: B-8.

Oliva, Paola. Te recuerdo, Pablo Neruda. Roma: Edizioni Associate, 2009.

Olivares, Edmundo. "Entusiasmo y perseverancia: Un texto fundacional". Nerudiana 4 (2007): 7-8.

Ortiz de Rosas, Marilú. “35 años sin Neruda”. El Mercurio. 23 sep. 2008: A-11. 
“Con furias y penas crece el mito nerudiano". El Mercurio. 22 nov. 2008: A-27.

Oses, Darío. "España en el corazón, facsímil de una edición legendaria”. Cuadernos Fundación Pablo Neruda 56 (2005): 116-119.

“La invención de la juventud”. Cuadernos Fundación Pablo Neruda 61 (2008): 70-82.

Prado, Benjamín. "Pablo Neruda, el Habitante de la Casa Inventada 2009". Cuadernos Hispanoamericanos 711 (2009): 57-63.

Quezada, Jaime. "Neruda en la UNESCO”. Nerudiana 1 (2006): 23-26.

"N.N.N: Neruda - Nueva York - Naciones Unidas". Nerudiana 6 (2008): 18-19.

Robertson, Enrique y Hernán Loyola. "Esfera, Pez y Hexagrama: el logo de Pablo Neruda". Nerudiana 3 (2007): 1-7.

"Según medios norteamericanos: Pablo Neruda inspira temas del mejor disco clásico de 2006. Lo interpreta la fallecida mezzosoprano Lorraine Hunt junto a la Sinfónica de Boston dirigida por James Levine". El Mercurio. 22 dic. 2006: A-13.

Selman Calavaro, Carla. "Junto con Tagore y Césaire: UNESCO se la juega por Neruda". El Mercurio. 24 nov. 2008: A-9.

Skirius, John, comp. El ensayo hispanoamericano del siglo XX. México: Fondo de Cultura Económica, 2005.

Sotta Donoso, Romina de la. "Guillermo Núñez rescata el Neruda más doliente". El Mercurio. 15 sep. 2008: A-11.

Teachout, Terry, Alex Ross y Peter Lieberson. "Luciana and Lorraine sing Neruda". Nerudiana 4 (2007): 26-27.

Thompson, Colin. "Robert Pring-Mill - Oxford Spanish don and Nerudista". The Independent. 15 de octubre de 2005. http://www.independent.co.uk/news/obituaries/robert-pringmill-511000. html.

Trujillo, Carlos y Milton Rogovin. Nada queda atrás. Chile: Ediciones Museo de Arte Contemporáneo Chiloé, 2007.

T. S. "Visita a Isla Negra: Príncipe de Noruega fascinado con el océano que inspiró a Neruda". El Mercurio. 27 ene. 2008: A-16.

Udbhavana 70. India, 2006.

Valdovinos, Mario. "La póstuma Elegía de Moscú”. Nerudiana 5 (2008): 18-19

Valenzuela, Adriana. "Santiago Vivanco: Exposición de Neruda en Cáceres". Nerudiana 8 (2009): 30 .

Varas, José Miguel. Tal vez nunca: Crónicas nerudianas. Santiago: Editorial Universitaria, 2008.

Vivanco S., Santiago. "Mesa y mantel con Pablo Neruda". Pablo Neruda en Santander: Primer Encuentro. Santander: Edición Obra Social Caja Cantabria, 2008. 43-56. 